\title{
Quest for a New Instrument for Measuring Academic Program Quality
}

\author{
Kaushik Mandal ${ }^{1}$, Chandan Kumar Banerjee ${ }^{1} \&$ Iwona Otola $^{2}$ \\ ${ }^{1}$ Department of Management Studies, National Institute of Technology Durgapur, West Bengal, India \\ ${ }^{2}$ Czestochowa University of Technology, Faculty of Management, Czestochowa, Poland \\ Correspondence: Kaushik Mandal, Department of Management Studies, National Institute of Technology Durgapur, \\ Mahatma Gandhi Avenue, Durgapur-713209, West Bengal, India. E-mail: kaushikmandal.nit@gmail.com
}

Received: July 2, 2019

Accepted: November 15, 2019

Online Published: December 22, 2019

doi:10.5430/rwe.v10n4p40

URL: https://doi.org/10.5430/rwe.v10n4p40

\begin{abstract}
This research explores and confirms a new way of measuring the quality aspect of an academic program based on hospitality education. In our opinion, there is a growing demand for specialists in hospitality education in India. The fact that the number of hospitality education institutes is increasing doesn't go hand in hand with the care for the quality of education. Hence, we present one set an alternative trajectory by offering a new instrument APQUAL for measurement of quality of hospitality program offered by an educational institute. A critical review of the literature on the major instrument for measuring higher education quality has been done. The empirical part of the paper presents the developed in eight steps APQUAL construct that is an effective instrument to analyze the academic program quality. This work explored a number of facets of program quality by employing EFA (exploratory factor analysis) and CFA (confirmatory factor analysis) to fit the first order nonrecursive model and calculated the reliability and validity of our proposed instrument. This research provides a valid measure of academic program quality, which can be also applicable at the micro-level.
\end{abstract}

Keywords: service quality management, measuring instrument, higher education, academic program quality, APQUAL, exploratory factor analysis

\section{Introduction}

The services sector affects the social and economic development of the country. It is a fundamental component of GDP, and indirectly affects the increase in productivity and development of other sectors. The growth of the service sector depends on certain facts and among them, not only the quantity but also the quality of service manpower is most crucial. Observations of the industry especially in a developing country like India reveal the same (Subbarao, 2008). In India studying the scenario of hospitality education, it is observed that the growth of the sector is mainly led by private sector initiatives. In India studying the scenario of hospitality education, it is observed that the growth of the sector is mainly led by private sector initiatives. Alternatively, the Government has not taken enough initiatives to establish a sufficient number of hospitality education institutes. However, there are genuine concerns about the quality of many of these private institutes (Agarwal, 2006). Basheka et al., (2009) pointed out that the entry of private service providers of higher education has caused a decline in the quality of graduates. Similarly, Lawrence (2008) has noticed that the quantitative expansion of higher education degrees in South East Asia has led to a qualitative problem. A survey by the Ministry of tourism, Govt. of India in 2011, indicates that there is a demand for .203 million trained hospitality professionals every year of which two-third is at the skill level and one third at managerial level. Hence it reveals that there is a huge gap in demand-supply in the hospitality sector. This gap further increases when existing supplies are unemployable. Thus it hampers the overall development of the country. Thus this may be viewed as a problem of lack of human resource development with a special reference to hospitality education referred after Hospitality Program (HP). The prime reason behind the shortage of employable human resources may be seen as a sub-optimal standard of academic services students are consumed during their formal training. Thus it became a problem of managing the service quality of educational institutes who are offering HP. Causes behind this low quality of HP are multitude as observed by researchers. Low quality of the academic curriculum, lack of proper pedagogy, ignoring industry requirements are the most identified causes (Banerjee \& Mandal, 2014). The evaluation system has not been made benchmarked as per the industry requirements. As a result of this most of the students do not have adequate skill-set to match the industry standard. Since job requirements are continuously changing it is quite difficult to produce tailor-made output unless there is regular and structured 
interaction between academia and industries. Higher education is a multi-stakeholder segment, including students, parents, faculty, alumni, industry, and society (Mandal \& Banerjee, 2012). Hence, it is necessary to measure the quality from each stakeholder's perception. However, faculty and industry are two major stakeholders in this segment. The faculty, as internal stakeholders in the Hospitality Program (HP), maybe in the right position to evaluate the quality of their own program. On the other hand industry experts, as external stakeholders may also be able to assess the quality of the HP by evaluating the students who have completed the program and either aspiring or working in the industry. In fact, faculty and industry experts both can work as program designer (and also evaluator) for HP.

\section{Literature Review}

Quality assurance and quality enhancement have become an integral part of the higher education system (Lomas, 2007). Pervasive competitive pressures to attract and retain prospective students and their guardians (education consumers) have made higher education systems ready to pay more attention to quality issues (Douglas et al., 2008). In fact, service quality and standards continue to be a major focus in the higher education sector like other industries (Green et al., 2008). However, the quality level in higher education is based on multiple aspects of service delivery including the teaching, training and placement service (Koong et al., 2011). In addition, communication and industry orientation must adhere to industry standards (Wickramasinghe and Sharma, 2005; Nadkarni, 2004). Harvey and Green (1993a) have argued that quality in higher education is a complex and multifaceted concept and still it is lacking an appropriate definition. Most of the related research works try to match their research in line with the service quality dimensions proposed by Parasuraman et al., (1988). Since higher education service is different from any other service it is unwise to befitting in the structure of SERVQUAL (Parasuraman et al., 1988). Furthermore, there are still no common instruments for measuring the quality of the Hospitality Program (HP) (Horng\& Teng, 2011). Earlier research explored how total quality management (TQM) is implemented in the higher education sector (Zabadi, 2013). Cronin and Taylor (1992) introduce the SERVPERF model which is found to have a good model fit in the settings where the importance of performance is high compared with expectations namely higher education and information systems (Landrum et al., 2010). Besides few of the research introduced general higher education evaluation models like higher education performance model (HEdPREF) by Abdullah (2006), technical education quality measurement scale (EduQUAL) by Mahapatra and Khan (2007) need attention for academic program-specific refinement. Since the hospitality program is having certain features special to the said program, it needs a customized measurement of service quality. In fact, an academic program in hospitality calls for 'co-creation' with the active participation of industry and academics. Hence, it seems, there is a need to redesign the present hospitality program includes curriculum as well as pedagogy. Executive prefers industry-ready employees in terms of skill set (Lefever \&Withiam, 1998). Goodman and Sprague (1991), find that students of hospitality education would remain in the industry longer if they have a strong basic understanding of what is expected from them by industry. However, assessing quality in higher education is a challenging task because the meaning of 'quality' is varied among different stakeholders (Becket \& Brookes, 2008). There are various internal and external stakeholders within higher education who are likely to have different or even contradictory views of quality. In fact, the presence of various stakeholders in the service generation process and their varied perceptions of quality have stated in the marketing literature (Daily et al., 2006). Cheng and Tam (1997) have opined that education quality is an unclear and debatable concept. Likewise, Pounder (1999) has argued that it appears with varied meanings for diverse stakeholders. Therefore, it is not easy to defining and measuring quality. Its measurement and management have naturally proved to be controversial. There are several ways to define quality such as i) excellence, ii) zero errors, iii) fitness with the purposes, iv) threshold, v) value for money, vi) enhancement or improvement (Campell \& Rozsnayi, 2002). The definition generates different approaches and reveals the number of measures for quality assessment. When implemented in higher education contexts quality as perceived by the executive has not able to justify all the aspects. Therefore, the concept of quality is not free from cross arguments (Harvey \& Green, 1993b; El-Khawas, 1998; Birnbaum \& Deshotels, 1999; Campell \& Rozsnyani, 2002). The term quality, as used in the manufacturing industry is needed to be redefined and relevant in the context of higher education (Fatma, 2006). Hence, quality dimensions (including quality attributes) and quality evaluation processes for the academic program namely HP are required to be identified and analyzed. Quality dimensions are different pedagogic phenomena, and different process variables, that describe the quality of a program (Gibbs, 2010). According to Cullen et al., (2003), it is a challenging task to produce a quality management framework Although measuring quality in higher education is becoming increasingly important for the educational institutes for attracting and retaining students (Angell et al., 2008). There are lots of controversies on the dimensions of educational quality and how it should be measured (Robbins, 2005). All these debates can be resolved by considering industry requirement as the benchmark for defining quality and it 
calls for developing an instrument in reference to said benchmark to measure the same for an academic institute runs HP.

In this context, the contributions of few other models, like, performance only model (SERVPERF) introduced by Cronin and Taylor (1992), the evaluated performance and normed quality model that has been projected by Teas (1993), as well as the newest, the service quality scale for online distance learning programs (DL-sQUAL) initiated by some researchers (Zhiltsov, 2006,) have also been appreciated in the literature. Overall all these models suffer from two major limitations which we have discussed at the end of the literature review.

There are several measures have been developed for estimating the quality of higher education. Among them, three are particularly focused on hospitality education. These are i) EduQUAL ii) HEdPREF and iii) IHTLP. In the following table, we have compared these three instruments in nutshell (Table 1).

Table 1. The major instrument for measuring higher education quality

\begin{tabular}{|c|c|c|c|}
\hline Service quality models & $\begin{array}{l}\text { Higher education } \\
\text { performance only } \\
\text { model }\end{array}$ & $\begin{array}{l}\text { Quality measurement } \\
\text { instrument for technical } \\
\text { education }\end{array}$ & $\begin{array}{l}\text { An instrument for the } \\
\text { hospitality, tourism and } \\
\text { leisure programme }\end{array}$ \\
\hline Measuring instruments & HEdPREF & EduQUAL & IHTLP \\
\hline $\begin{array}{l}\text { Authors and year of } \\
\text { introduction }\end{array}$ & Firdaus Abdullah, 2006 & Mahapatra and Khan, 2007 & $\begin{array}{l}\text { Horng, Teng, and Baum, } \\
2009\end{array}$ \\
\hline \multirow[t]{6}{*}{ Quality Dimensions } & Non-academic aspects & Learning outcomes & Strategic planning \\
\hline & Academic aspects & Responsiveness & Curriculum and instruction \\
\hline & Reputation & Physical facilities & Spaces \\
\hline & Access & Personality development & Faculty \\
\hline & Programme issues & Academics & Student achievements \\
\hline & & & Administrative management \\
\hline \multirow[t]{4}{*}{ Sample population } & Students & Students, & Full-time teachers \\
\hline & & Alumni, & \\
\hline & & Parents of student & \\
\hline & & Recruiters & \\
\hline
\end{tabular}

Among these three instruments proponents of HEdPREF (2006) and IHLTP (2009) consider no views from the industry. Whereas Mahapatra and Khan (2007) in developing EduQUAL recognize the importance of multiple stakeholders for measuring the quality of the HP but not emphasized the views of the industry as a benchmark of quality. Others also have an opinion to run professional programs like HP convergence of industry view with academia (Law, 1983). In this context, the research work of Banerjee and Mandal (2014) may be mentioned, who opined the opinion gap in the hospitality management curriculum between executives and faculty. Hence, all of this literature advocates the need for an alternative measure for higher education that employs industry view as a benchmark. Therefore, in this research, we show our intention to develop a valid construct for measuring the quality of HP and also investigate the relative importance given to each of the dimensions by industry and academia.

The review of the literature reveals that all the previous studies are more or less concerned about the measurements of higher education quality but not emphasized on the most important dimension of education service quality and that is 'academic program quality'. In addition, most of the previous studies have considered the views of either academia or industry while measuring educational quality but the opinions of both industry and academia at a time are not executed. Hence in the next section, we try to explore the relevant issues regarding the quality of the 'Academic Program'.

The review of the literature reveals that all the previous studies are more or less concerned about the measurements of higher education quality but not emphasized on the most important dimension of education service quality and that is 'academic program quality'. In addition, most of the previous studies have considered the views of either academia or industry while measuring educational quality but the opinions of both industry and academia at a time are not executed. Hence in the next section, we try to explore the relevant issues regarding the quality of the 'Academic Program'. 


\subsection{Academic Program Quality}

Both academic and industry experts believe that academic program quality is the backbone of educational quality and as a result of these the mission for developing a systematic procedure for measuring academic program quality has been started since the mid-1980s. Researchers reveal various significant dimensions of academic program quality which are considered as crucial for evaluating the quality of a programme of an educational perspective. For instance, Gupta and Mandal (2017) observed some quality standards for higher education among which 'curriculum of study program' was considered one of the priorities. In reference to achieving the teaching standard in educational technology, Abate (2003) also have given emphasize on curriculum standard and pedagogy. In the quest of identifying the highest important factors for the distance learning program at the open university of Malaysia (OUM), Latif and Bahroom (2010) have mentioned the significance of 'Teaching and learning 'and facilities. Banerjee and Mandal (2014) were also focused on the issue of curriculum development for professional education. Joseph and Joseph(1997) have considered syllabus designing, teaching methods and teaching aids (pedagogy) as important elements of the teaching-learning system. He has demonstrated that the right curriculum can bring sustainability to the tourism development of small island states in the Caribbean. Thus, it relates curriculum framing with the quality of the academic program. Therefore, it is evident that the right curriculum and teaching pedagogy are crucial for an academic program. In this respect, Mandal and Gupta (2018) have opined that a course should be designed, developed and improved continuously in order to provide the students with knowledge as desired in the instructional goal.

However, some of the experts believe that besides curriculum and pedagogy, a few other dimensions are also vital for an ideal academic program. Gupta and Mandal (2017) argued that practical training is one of the key elements of the academic program which links theoretical studies with practice. On the other hand, Latif and Bahroom (2010) have also advocated the idea that communication skills were paramount life skills for a student. The authors have mentioned that communication skills, both written and oral, are the most significant quality employers seek in the 'ideal candidate'. Another report (Ballantyne \& Rivera, 2014) indicated that "communication" and "foreign language proficiency" are the inevitable aspects of a modern academic program and international exposure adequately prepares for international practice (Jones et.al., 1999). Thus based on all identified issues vis-à-vis academic program quality we have to proceed for the development of an instrument since no such measure has been developed yet. In fact, further, we have accommodated views of both faculty members and industry experts to purify the same.

\section{Construction of APQUAL - Methodology and Results}

The composition of the development and validation of a construct was based on the methodology proposed by Churchill (1979). This method comprises eight steps (Figure 1).

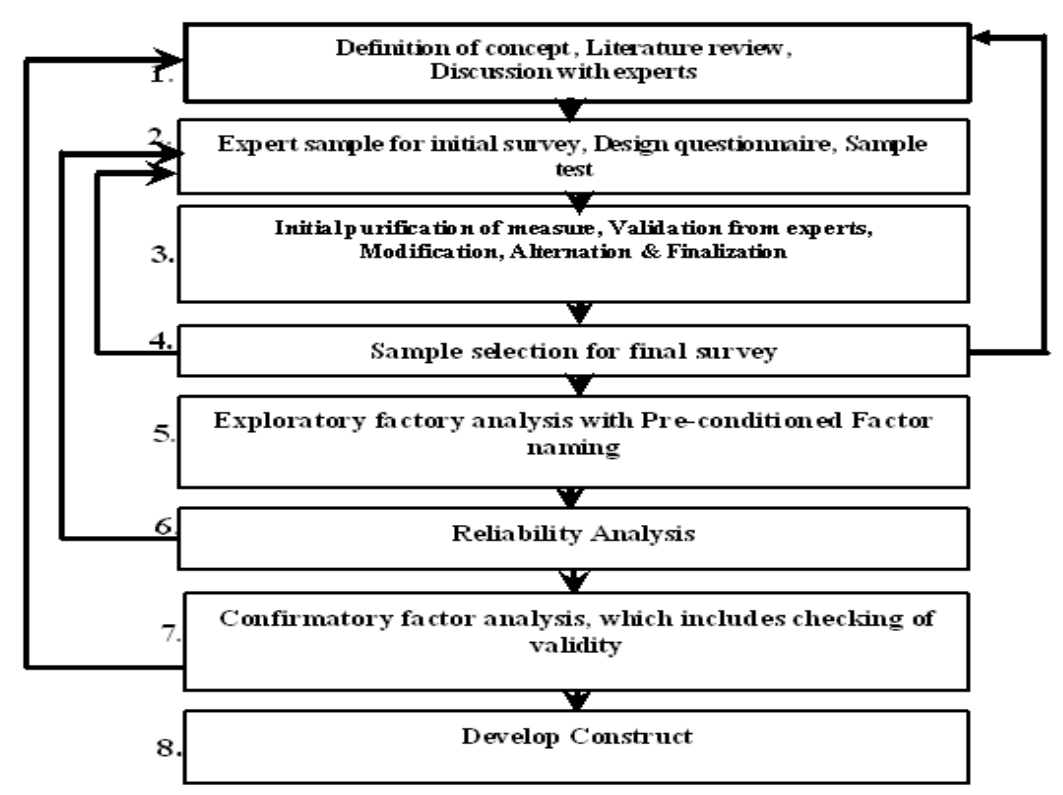

Figure 1. Construct development procedure 
In the first step, we have defined the concept and carried out a comprehensive review of the existing literature to determine the essential quality dimensions of HP. Based on initial identification we discussed with the experts chosen from industry and academics. In the second step, a draft has been developed by the expert panel with 32 quality attributes in the form of statements for the survey purpose. Further (step 3), the questionnaire with its 35 statements has been designed and appraised by means of a pilot test. In order to purify the instrument, the questionnaire survey has been conducted using respondents who are full-time faculty in HEI (higher education institutions) and executives in hotels with more than ten years of experience. The institutes offer hospitality and tourism education under the West Bengal University of Technology and five-star category hotels located in West Bengal, a state of India, have been selected randomly for the identification and selection of experts for the pilot survey. In fact, 10 hospitality management institutes and 10-star category hotels respectively have been selected for the purpose. Out of 280 questionnaires distributed, but only 151 valid questionnaires were obtained, with a response rate of $53.92 \%$. After initial purification, 9 items have been eliminated from the questionnaire as per the suggestion of the experts and initial survey results. In the end, 26 items have been selected for the final survey. Responses for the final survey have been collected from the same two separate randomly groups from West Bengal, India (step 4). One group consists of academic experts i.e faculties from HEI and other group includes top and middle-level professionals of HP. 150 experts from HEI and 142 experts from HP have been participated in the last survey and out of 292 distributed questionnaires with a rate of $64.72 \%, 189$ have been responded. In step 5 we have checked adequacy and suitability of data before the execution of Exploratory Factor Analysis (EFA). Kaiser-Meyer-Olkin Measure (KMO) of Sampling Adequacy and Bartlett's Test of Sphericity provide the suitability of the assumption for carrying out of EFA. KMO value is 0.655 , which signifies that the correlation matrix is sufficiently away from the identity matrix since the result of Bartlett's Test of Sphericity shows a value 552.803, (p<0.005) (Field, 2009). This further relates to the satisfactory interdependence of the variables. Thus both the results support efficient latent factor identification through 'Principal Component Analysis'.

In step 5 using exploratory factor analysis (EFA), we have measured academic program quality and distinguished six factors with 16 items that explained almost $60 \%$ of the variability. There are following factors: degree of industry focusness of the program (F1), quality related to curriculum and pedagogy (F2), international competence of the program (F3), technical competence of the program (F4), global exposure of the program (F5), industry readiness of the program (F6). Each of these factors indicates a distinguishable dimension. Respectively we used reliability analysis (RA) to purify the developed construct (step 6). Cronbach's Alpha (CA) and composite reliability (CR) are two important measures and value for both is acceptable beyond 0.6 (Fornel\& Larker, 1981). The calculated CA and CR values were released for including the F1, F2, F3 and F5 factors for final confirmatory model building (table 2).

Table 2. Results for reliability analysis

\begin{tabular}{lllllll}
\hline & F1 & F2 & F3 & F4 & F5 & F6 \\
\hline Cronbach's Alpha (CA) & 0.688 & 0.602 & 0.607 & 0.482 & 0.501 & 0.438 \\
Composite Reliability (CR) & 0.774 & 0.758 & 0.735 & 0.725 & 0.597 & 0.583 \\
\hline
\end{tabular}

In step 7 we have validated the instrument by confirmatory factor analysis (CFA) (Fornel and Larker,1981) using AMOS (Analysis of moment structure version 7) software. This analysis has been executed mainly to determine the goodness of fit between the hypothesized model \& sample data. Moreover, this analysis provides the idea for path addition to improving the goodness fit of the proposed EFA model. We have developed two models of CFA: initial Model A and the final Model B of academic programme quality (APQUAL). The results for both contending models with the recommended values by several researchers indicate that the proposed models fit (Appendix I). The scores acquire from the second order analysis for Model B indicate an excellent fit between the data and the model. All the fit index conforms to the values recommended by Hair et al. (1998). Moreover, the CMIN/DF (1.221) is also within the excepted or recommended value for Model B. On the basis of the obtained results, it is apparent that Model B is well supported and better fit than Model A. Therefore, we can conclude that all the four factors (F1, F2, F3, F5) tested in this study are emerging to be extremely appropriate for measuring academic program quality of higher education institutions. Model B fits better as it establishes the significance of four factors that are essential for measuring academic programme quality of a higher education institute. Hence, Model B has been accepted.

In the last step, we proposed the 'APQUAL' model. The proposed APQUAL model fits because it passes all the goodness of fit and the minimum recommended values of acceptability. The APQUAL model has proved to be 
effective for measuring academic program quality of the higher education sector as a whole.

\section{Discussion}

The newly developed APQUAL instrument consists of four quality dimensions those are i) Industry focuses of the program, ii) Quality related to curriculum and pedagogy, iii) International competence of the program and iv) Global exposure of the program. The findings of this study reveals that among the four dimensions, "Degree of industry focusness of the program (F1)", "Quality related to curriculum and pedagogy (F2)" and "International competence of the program (F3)" are the most important factors in HP, since the composite reliability associated with F1, F2 and F3 are more than 0.7 and that is good enough. Now, there is an obvious question that arises in this context whether this newly developed APQUAL instrument can be used in academic institutes to determine their programme quality or not. The applicability of this new instrument will have to be proved through some empirical testing. The test result of the APQUAL model will be presented in the next article.

\section{Conclusion}

This newly developed APQUAL instrument can also be used in professional or technical institutions for evaluating their academic programme quality. Furthermore, in terms of practical application, the APQUAL instrument will be useful for both practitioners and researchers. Practitioners (academia and industry) can use this construct to evaluate the extent of the quality of the program they provide to their customers (students) and to spot those dimensions and attributes, which their organizations require, for improvement. For academia, this instrument contributes significantly to the existing higher education programme by comparing the industry standard and actual practices and identifies the perceived gaps in academic programme quality. APQUAL instrument can be a unique instrument for Industry for assessing the quality of the academic programme, a particular professional programme such as hospitality management, engineering, business management etc. and the output produced by the HEI. APQUAL instruments can also be used in order to prepare the students as per industry standards. For researchers, this study contributes significantly to the existing literature by developing an instrument like APQUAL. The findings of this research confirm the conclusion that the APQUAL instrument developed in this research is not only helpful for measuring the quality of HP only but also useful for the entire higher education sector. This research tantamount to two broad applications: i) Provide a valid measure of academic program quality (APQ) ii) This aggregative model can also be applicable at micro-level. Each Institute can measure the 'Gap' between industry expected value and score of that said institute (as perceived by the faculty members) in relation to APQ facets.

\section{References}

Abate, M.A., Stamatakis, M.K., \& Haggett, R.R. (2003). Excellence in curriculum development and assessment. American Journal of Pharmaceutical Education, 67(3), 89.

Abdullah, F. (2006). The development of HEdPERF: a new measuring instrument of service quality for the higher education sector. International Journal of Consumer Studies, 30(6), 569-581.

Agarwal, P. (2006). Higher education in India the need for change. Indian Council for Research on International Economic Relations, WP no.180.

Angell, R.J., Heffernan, T.W., \& Megicks, P. (2008). Service quality in postgraduate education. Quality Assurance in Education, 16(3), 236-254.

Ballantyne, K., \& Rivera, C. (2014). Language Proficiency for academic achievement in the international Baccalaureate Diploma Program. Report. The GeorgeWashington University Centre for Equity and Excellence in Education.

Banerjee, C.K., \& Mandal, K. (2014). A comparison of academia and industry perceptions of an ideal hospitality management programme. International Journal of Services, Economics and Management, 6(2), 146-162.

Basheka, B.C., Muhenda, M.B., \& Kittobe, J. (2009). Programme Delivery, Quality Benchmarks and Outcomes Based Education at Uganda Management Institute: A correlational approach. NCHE, Kampala.

Becket, N., \& Brookes, M. (2008). Quality Management Practice in Higher Education -What quality are we actually enhancing?. Journal of Hospitality, Leisure, Sports and Tourism Education, 7(1), 40-54.

Birnbaum, R., \& Deshotels, J. (1999). Has the academy adopted TQM?. Planning for Higher Education, 28(1), 29-37.

Campell, C., \& Rozsnyani, C. (2002). Quality Assurance and the Development of Course Programs. Papers on Higher Education. Unesco-CEPES, Bucharest. 
Cheng, Y., \& Tam, W. (1997). Multi-Models of Quality in Education. Quality Assurance in Education, 5(1), 22-31.

Churchill, G.A. Jr. (1979). A paradigm for developing better measures of marketing constructs. Journal of Marketing Research, 16, 64-73.

Cronin, J.J., \& Taylor, S.A. (1992). Measuring service quality: reexamination and extension. Journal of Marketing, $56,55-68$.

Cullen, J., Joyce, J., Hassall, T., \& Broadbent, M. (2003). Quality in Higher Education: from Monitoring to Management. Quality Assurance in Education, 11(1), 30-34.

Daily, B.F., Weisinger, J.Y., Holman, N., \& Govindarajulu, N. (2006). The Deming framework as context for exploring cost of quality in arts and cultural organizations. International Journal of Services and Standards, 2, 349-367.

Douglas, J., McClelland, R., \& Davies, J. (2008). The development of a conceptual model of student satisfaction with their experience in higher education. Quality Assurance in Education, 16(1), 19-35.

El-Khawas, E. (1998). Quality Assessment in Higher Education: Recent Progress; Challenges Behind. The World Bank, Washington, DC.

Fatma, M. (2006). A systems approach to program evaluation model for quality in higher education. Quality Assurance in Education, 14(1), 37-53.

Field, A. (2009). Discovering statistics using SPSS. Sage publications, London.

Fornell, C., \& Larcker, D.F. (1981). Evaluating Structural Equation Models with Unobservable Variables and Measurement Error. Journal of Marketing Research, 18(1), 39-50.

Goodman, R.J., \& Sprague, L.G. (1991). The future of hospitality education; meeting the industry's needs. The Cornell Hotel and Restaurant Administration Quarterly, 32(2), 66-69.

Green, Jr. K.W., Rudolph, L., \& Stark, C. (2008). Antecedents to service quality in a service centre environment. International Journal of Services and Standards, 4(2), 167-181.

Gupta, H., Mandal, K., \& Das, D. (2017). Student Orientations towards course and its impact: an empirical study on pharmacy student. International Journal of Economic Research, 14(8), 397-406.

Hair, F.J., Black, C.W., Badin, N.J., Anderson, E.R., \& Tatham, R.L. (2005). Multivariate Data Analysis. New Joursey, Pearson Education Inc.

Harvey, L., \& Green, D. (1993a). Assessing quality in higher education: a transbinary research project. Assessment and Evaluation in Higher Education, 18(2), 143-149.

Harvey, L., \& Green, D. (1993b). Defining quality. Assessment \& Evaluation in Higher Education, 18(1), 9-34.

Horng, J.S., \& Teng, C.C. (2011). Cross-cultural quality measurement of undergraduate hospitality, tourism and leisure programmes: Comparisons between Taiwan and the USA. Journal of Hospitality, Leisure, Sport and Tourism Education, 10(1), 49-62.

Jones, J.F. (1999). From silence to talk: Cross cultural ideas on students' participation in academic group discussion. English for specific purposes, 18, 243-259.

Koong, K.S., Flores, J., \& Liu, L.C. (2011). Health information technology performance measures: a lifecycle analysis. International Journal of Services and Standards, 7(3/4), 181-196.

Landrum, H., Prybutok, V.R., Peak, D., \& Qin, H. (2010). Using importance ratings to create an information service quality measure. International Journal of Services and Standards, 6(3-4), 295-307.

Latif, L.A., \& Bahroom, R. (2010). OUM's tracer study: A testimony to a quality open and distance education. ASEAN Journal of Open and Distance Learning, 2(1), 35-47.

Lefever, M., \&Withiam, C. (1998). Curriculum review: how industry views hospitality education. Cornell Hotel and Restaurant Administration Quarterly, 39(4), 70-78.

Lomas, L. (2007). Zen, motorcycle maintenance and quality in higher education. Quality Assurance in Education, 15(4), 402-412.

Mahapatra, S.S., \& Khan, M.S. (2007). A neural network approach for assessing quality in technical education: an empirical study. International Journal of Productivity and Quality Management, 2(3), 287-306.

Malhotra, N. K. (2007). Review of marketing research. In Review of Marketing Research (pp. v-v). Emerald Group 
Publishing Limited.

Mandal, K., \& Banerjee, C. (2012). A search for measuring quality in engineering education: an empirical study. ZENITH International Journal of Business Economics and Management Research, 2(3), 50-67.

Mandal, K., \& Gupta, H. (2018). Service Quality Gap Measurement in Pharmaceutical Educational Institutes: An Empirical Analysis for Model Development. Indian Journal of Pharmaceutical Education and Research, 52(3), 351-362.

Nadkarni, P.M. (2004). Evolving standards for clinical content in biomedicine: overview and lessons. International Journal of Services and Standards, 1(1), 112-124.

Parasuraman, A., Zeithaml, V.A., \& Berry, L.L. (1988). Servqual: A multiple-item scale for measuring consumer perception of service quality. Journal of Retailing, 64(1), 12-40.

Pounder, J. (1999). Institutional Performance in Higher Education: is quality a relevant concept?. Quality Assurance in Education, 7(3), 56-163.

Robbins, D. (2005). Quality assurance. In D. Airey, \& J. Tribe (Eds.), An International Handbook of Tourism Education (pp. 451-468). Oxford, England: Elsevier.

Schreiber, J.B., Nora, A., Stage, F.K., Barlow, E.A., \& King, J. (2006). Reporting structural equation modelling and confirmatory factor analysis results: A review. The Journal of Educational Research, 99(6), 323-338.

Subbarao, S.P. (2008). Issues and Constrains in Manpower Supply in Indian Hospitality Industry. Indian Institute of Management Ahmedabad, W.P. No.2008-02-03.

Teas, R.K. (1993). Expectations, performance evaluation, and consumers' perceptions of quality. The Journal of Marketing, 57(4), 18-34.

Wickramasinghe, N., \& Sharma, S.K. (2005). Key considerations for ensuring high quality HIPAA compliant e-health. International Journal of Services and Standards, 1(3), 319-335.

Zabadi, A.M.A. (2013). Implementing Total Quality Management (TQM) on the Higher Education Institutions - A Conceptual Model. Journal of Finance \& Economics, 1(1), 42-60.

Zhiltsov, M. (2006). Service quality models. TU-91.167. Seminar in Business Strategy and International Business.

\section{Appendix I}

Results of Confirmatory Factor Analysis - Comparative Statement of Initial \& Final Model

\begin{tabular}{llll}
\hline Models & Recommended Value* & Model A & Model B \\
\hline Chi-square** & & 34.882 & 46.393 \\
df & & 36 & 38 \\
P & & 0.522 & 0.165 \\
RMR & $\geq 0.90$ & 0.104 & 0.123 \\
GFI & $\geq 0.90$ & 0.968 & 0.959 \\
AGFI & $\geq 0.5$ & 0.942 & 0.929 \\
PGFI & $\geq 0.90$ & 0.528 & 0.552 \\
NFI & $\geq 0.90$ & 0.905 & 0.874 \\
CFI & $\geq 0.90$ & 1.000 & 0.973 \\
TLI & & 1.005 & 0.961 \\
PNFI & & 0.593 & 0.604 \\
FMIN & $\leq 0.08$ & 0.186 & 0.247 \\
F0 & & 0.000 & 0.045 \\
RMSEA & 0.000 & 0.034 \\
AIC & $\geq 200$ & 94.882 & 102.393 \\
ECVI & $\leq 2 * *$ & 0.505 & 0.545 \\
Hoelter (.05) & 275 & 217 \\
CMIN/DF & & 0.969 & 1.221 \\
\hline
\end{tabular}

*Criteria according to Hair et al. (2005)

** Criteria according to Schreiber J.B., Nora A., Stage F. K., Barlow E.A., \& King, J. (2006); recommend chi-square/degrees of freedom value of $\leq 3.00$ 